\title{
Growth and Nutritional profile of Duckweed (Lemna minor) cultured with different organic manure
}

\author{
Okwuosa, Obinna Ben*1,2, Eyo, Joseph $\mathbf{E}^{2}$, Amadi-Ibiam, Christina $\mathrm{O}^{3}$ \\ ${ }^{1}$ Department of Science Laboratory Technology, Akanu Ibiam Federal Polytechnic, Unwana. \\ ${ }^{2}$ Department of Zoology and Environmental Science, University of Nigeria, Nsukka. \\ ${ }^{3}$ Department of Fisheries and Aquaculture, Ebonyi State University, Nigeria
}

\begin{abstract}
A thirty days growth trial was conducted to evaluate the growth characteristics and proximate composition of duckweed (Lemna minor) cultured in poultry (T1), pig(T2) and cattle dungs(T3) with a 9 fiber glass tanks of $1 \mathrm{~m} \times 0.5 \mathrm{~m}$ $\mathrm{x} 0.5 \mathrm{~m}$ square that is already enriched with the organic manure in triplicates. Observation revealed that biomass increase occurred every day. Harvesting was carried out every four days for five times successfully and total yield was $18.20 \mathrm{~kg}$ for poultry media, $11.30 \mathrm{~kg}$ for pig dung media and 19,30kg respectively. The growth of duckweed harvested from various media were air-dried and representative samples taken for proximate analysis. The proximate composition of the three samples were compared, the results obtained showed that crude protein recorded $(7.50 \%$ in $\mathrm{T} 1,10.18 \%$ in $\mathrm{T} 2$ and $9.55 \%$ in T3), crude fibre (12.24\% in T1, $10.52 \%$ in $\mathrm{T} 2$ and $11.78 \%$ in $\mathrm{T} 3)$, ash $(13.14 \%$ in $\mathrm{T} 1,11.75 \%$ in $\mathrm{T} 2$ and $13.95 \%$ in $\mathrm{T} 3)$, dry matter $(9.89 \%$ in $\mathrm{T} 1,7.53 \%$ in $\mathrm{T} 2$ and $8.15 \%$ in $\mathrm{T} 3)$, nitrogen free extract $(1.20 \% \%$ in $\mathrm{T} 1,1.63$ in $\mathrm{T} 2$ and 1.52 in T3), moisture conten $(9.89 \%$ in $\mathrm{T} 1,7.53 \%$ in $\mathrm{T} 2$ and $8.15 \%$ in $\mathrm{T} 3)$, fat $(2.24 \%$ in $\mathrm{T} 1,1.95 \%$ in $\mathrm{T} 2$ and $2.28 \%$ in $\mathrm{T} 3)$, and carbohydrate $(55.00 \%$ in $\mathrm{T} 1,58.07 \%$ in $\mathrm{T} 2$ and $54.00 \%$ in $\mathrm{T} 3$ ) fractions respectively. The proximate composition of the cultured duckweed appeared higher in all fractions beside the crude protein. However, irrespective of the medium where the duckweed was harvested, the crude protein value obtained suggested that duckweed can be incorporated into livestock feeds as a protein supplement, particularly when grown on nutrient rich mediums and in livestocks that does not require much protein like in tilapia.
\end{abstract}

\section{INTRODUCTION}

Biological, plant-based systems provide multi-functional life support functions, such as carbon-dioxide removal, oxygen production, water recovery, and waste recycling. Technologies that simultaneously remove waste, produce food, and purify water with a high resource use-efficiency will also advance sustainable agriculture on Earth, benefiting populations in regions with low water and nutrient availability. Aquatic plants can recover nutrients from metabolic waste streams, while their edible biomass can provide a protein rich dietary supplement to Aquatic Animals (Li et al., 2020) like fish. However, they have received little attention as potential food crops for space applications. Duckweed (family Lemnaceae) is a tiny flowering plant that offers enormous potential for bioregenerative space life support. It is one of the fastest growing plants in the world, growing on slow-flowing or still shallow water bodies. It thrives on wastewater rich in nutrients and dissolved organic compounds (i.e. waste). Duckweed is gaining global recognition as a powerful and ecologically friendly means of removing nutrients and other pollutants from wastewater. Moreover, duckweed has a very high protein content and very little fibrous material, making it not only edible, but also a valuable food supplement to diets lacking in protein. Protein-rich duckweed biomass is best known as feedstock for animals (e.g., fish, poultry, cattle), but is also harvested for human consumption in many countries.

The duckweed family (Lemnaceae) contains the smallest flowering plants on Earth (Journey et al., 1991) and is among the fastest growing plants in the world (Ziegler et al., 2015). There are four genera: Lemna, Spirodela, Wolffia, and Wolffiella, which include about 40 different species in total (Journey et al., 1991). Duckweed, shown in Figure 1, is a free-floating aquatic plant that is common in lakes, ponds, canals, rice fields, and ditches (Zhuang, 2014). It will occur in most still or slow-flowing water bodies under a wide range of conditions (except in nutrient-poor or highly acidic water) (Zhuang, 2014). It can even grow in a trickle of water over vertical surfaces, such as seepages in cliffs (Zhuang, 2014), on mud, or on water that is only millimeters deep (Leng, 1999). Though it is a flowering plant, duckweed primarily reproduces through vegetative budding. Over a 10-day period, an individual mother frond may produce up to 10 generations of daughter fronds before dying (Journey et al., 1991). Only occasionally does it produce tiny flowers and seeds (Journey et al., 1991). Duckweed has leaf-like ovoid parts, called fronds, with hair-like roots (thought to provide stability).8 Fronds range from 1-20 mm across, depending upon the species. Because little structural tissue is required for this buoyant floating plant, fronds contain $<5 \%$ fiber (Journey et al., 1991). Duckweed grows extremely fast, doubling 


\section{Vol. 8, Issue 12, December 2021}

\section{DOI: $10.17148 /$ IARJSET.2021.81202}

its biomass in 1-3 days, (Ziegler et al., 2015) under ideal conditions. In addition to its nutritional value and fast growth, these plants can purify highly concentrated waste streams into safe drinking water.

The biomass of duckweed also doubles in 2 to 3 days (Skillicorn et al., 1993) under ideal conditions of nutrient availability, sunlight, $\mathrm{pH}(6.5-7.5)$, and temperature $\left(20^{\circ} \mathrm{C}\right.$ to $\left.30{ }^{\circ} \mathrm{C}\right)$. Generally, duckweed contains 6.8 to $45 \%$ crude protein (CP), 1.8 to $9.2 \%$ crude lipid (CL), 5.7 to $16.2 \%$ crude fiber, 12 to $27.6 \%$ ash, and the carbohydrate content is in the range of $14.1-43.6 \%$ on a dry matter basis (Landolt and Kandeler, 1987). The nutrient composition in each duckweed species varies depending on the condition of the water environment (Leng et al., 1995). Therefore, this study was designed to investigate the growth performance of duckweed using different media or sources of nutrients or environments to ascertain the nutritional composition of the duckweed fronds grown with different medias.
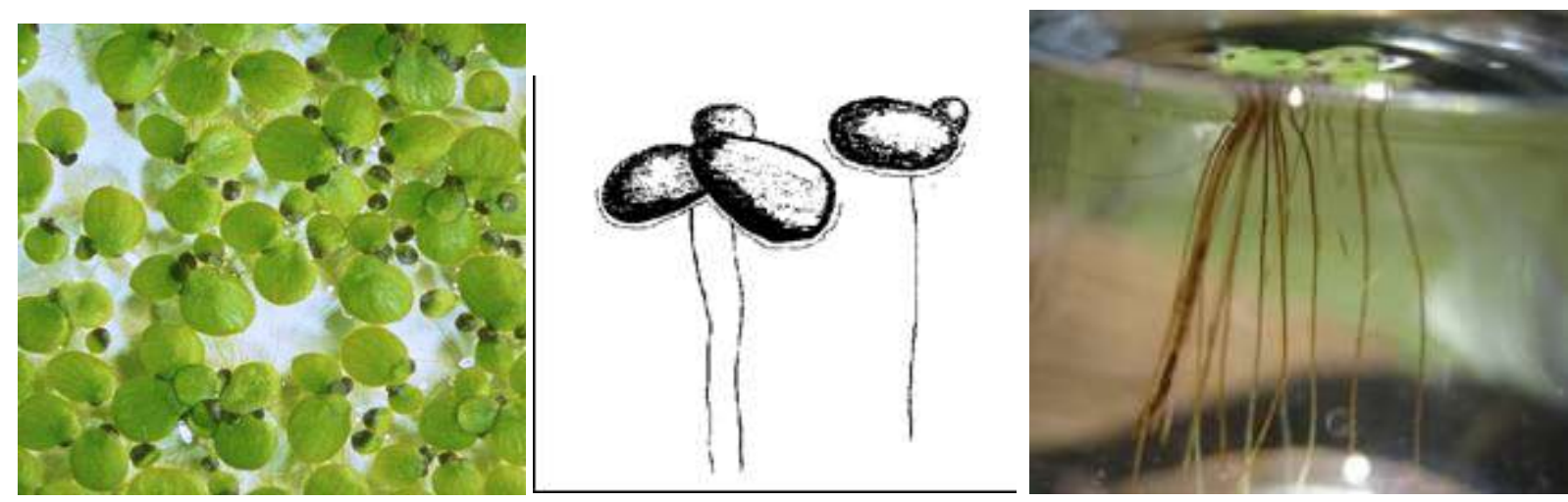

Figure 1. Lemnaceae (Duckweed Family, Lemna minor) (Cross, 2002).

\section{Hypothesis/Prediction}

The duckweed fronds that are in water contaminated by Poultry droppings should reproduce at a rate significantly higher than those contaminated with cow blood and cow dung, because they have more nutrients, provided by the contents of the poultry droppings. Duckweed reproduction is stimulated by the presence of nitrates and phosphates (Acosta, 2004). Consequently, there should be more growth in the containers with Poultry droppings and All Purpose plant food since poultry droppings contain more nitrates and phosphates.

\section{MATERIALS AND METHODS}

\section{Experimental site}

The field experiment was conducted at the Benoso farm, Afikpo Experimental Station. Afikpo spans an approximately 164 square kilometers in size. It is located on 6-degree north latitude and 8-degree east longitude. It occupies an area of about 64 square miles $\left(164 \mathrm{~km}^{2}\right)$. Afikpo is a hilly area despite occupying a region low in altitude, which rises 350 feet above sea level. It is a transitional area between open grassland and tropical forest and has an average annual rainfall of seventy-seven inches $(198 \mathrm{~cm})$.

\section{Experimental Design I}

$50 \mathrm{~g}$ of duckweed was introduced into 9 fiber glass tanks in triplicate for each dietary treatment each of $1 \mathrm{~m} \times 0.5 \mathrm{~m} \times 0.5 \mathrm{~m}$ square that was already enriched with organic manure. The relative growth rate (RGR) of L. minor varied among different treatments in all three experiments. Three ponds per treatment were contaminated with cow dung, pig dung and poultry droppings respectively. In experiment 1, 2 and 3, L. minor was harvested every week and the nutrient refresh with $20 \%$ of the initial $50 \mathrm{~g}$, during 30 days of culture period. The nutrient was refreshed weekly by addition of $20 \%$ of the initial nutrient size of the culture media. The growth level was recorded weekly till the end of $4^{\text {th }}$ weeks that the research was elapse. After culturing, the growth rate was compared within each week of harvest. The work area was cleared and set up. Also safety glasses and gardening gloves were worn.

\subsection{Experimental Design II}

Fresh duckweeds were analyzed for dry weight (DW). The growth of duckweed harvested from various media were airdried, finely ground and homogenized with a laboratory mill for small amounts for further use and representative samples taken for proximate analysis.

\section{Proximate analysis}

It involves an assay for all the representative samples constituents a sample. Each sample was taken to the laboratory in triplicate and the determinations of proximate compositions were carried out on each group. 


\section{International Advanced Research Journal in Science, Engineering and Technology}

Vol. 8, Issue 12, December 2021

DOI: $10.17148 /$ IARJSET.2021.81202

\section{Determination of moisture}

The moisture content of each fish samples was determined using the over drying method following the method of AOAC (2000).

\section{Determination of ash}

Ash content of fish samples was determined by incineration in a carbolated Sheffield LMFs Muffle Furnace at $500^{\circ} \mathrm{C}$ (AOAC, 2000).

\section{Determination of protein}

The total nitrogen (crude protein) was determined using the Kjeldahl method (AOAC, 2000).

\section{Determination of carbohydrate}

The carbohydrate content was calculated by difference \% $\%$ CHO= Dry biomass $100-($ Sum of the percentage of moisture, ash, lipid, protein and mineral)

Data Analysis

Data were presented as mean \pm SE unless otherwise stated. Data were analyzed using one-way analysis of variance (ANOVA), Duncan's multiple range test, DMR (Montgomery, 1984) and, where appropriate, by Student's t-test (SPSS software 19.0). Statistical significance was accepted at $\mathrm{P}<0.05$ level.

\section{RESULTS AND DISCUSSION}

The rising world population and the improving living standards have been driving the increase of animal and plant-based protein consumption making it scarce and expensive. So, there is need for alternative source of protein that is available and less costly to produce hence duckweed. This study therefore focused on evaluating the growth and proximate compositions of duckweed using different culture media with the aim getting a better and less costly medium of growing duckweed as shown in the results below.

Table 1: Growth variations of Lemna minor cultured in different nutrients

\begin{tabular}{llll}
\hline Parameters & T1 & T2 & T3 \\
\hline Initial weight $(\mathrm{g})$ & 50 & 50 & 50 \\
Final weight $(\mathrm{g})$ & 1870 & 1180 & 1980 \\
Weight gain $(\mathrm{g})$ & 1820 & 1130 & 1930 \\
Daily weight gain $(\mathrm{g})$ & 60.67 & 37.76 & 64.33 \\
\% daily growth rate & 3.33 & 3.34 & 3.33 \\
\hline
\end{tabular}

TI= POULTRY DROPPINGS T2= PIG DUNGS T3= CATTLE DUNGS

Table 2: Proximate composition of Lemna minor cultured in different nutrients

\begin{tabular}{llll}
\hline PARAMETERS & T1 & T2 & T3 \\
\hline N & $1.20 \pm 1.13$ & $1.63 \pm 0.81$ & $1.52 \pm 0.31$ \\
CP & $7.50 \pm 1.13$ & $10.18 \pm 0.79$ & $9.55 \pm 0.34$ \\
M.C & $9.89 \pm 1.12$ & $7.53 \pm 0.81$ & $8.15 \pm 0.31$ \\
ASH & $13.14 \pm 0.17$ & $11.75 \pm 1.08$ & $13.95 \pm 0.90$ \\
CF & $12.24 \pm 0.82$ & $10.52 \pm 1.12$ & $11.78 \pm 0.30$ \\
FAT & $2.24 \pm 0.05$ & $1.95 \pm 0.97$ & $2.58 \pm 1.03$ \\
CHO & $55.00 \pm 0.33$ & $58.07 \pm 1.12$ & $54.00 \pm 0.80$ \\
\hline
\end{tabular}

DM-Dry Matter, CP-Crude Protein, CHO-Carbohydrate, CF-Crude Fibre MC- Moisture content

\section{Culture of $L$. minor in Outdoor Tanks \\ Water Quality}

Three consecutive experiments were conducted in outdoor tanks to generate the baseline data for the production of duckweed L. minor in the pond conditions. Four, three, and two different manures were used in experiments 1, 2, and 3, respectively. In the pond experiment, only Organic Manure were applied for the production of $L$. minor. In experiment 1 , water temperature ranged from $27.0 \pm 0.06$ to $28.5 \pm 0.7 \circ \mathrm{C}$ in various treatments during July-August 2019. The intensity of light was recorded as $6,834 \pm 162$ to $5,542 \pm 127$ lux during this period in different culture tanks. There was no significant $(\mathrm{P}>0.05)$ difference in water temperature and light intensity among various culture tanks. Water temperature and light intensity were higher at the beginning of the study and gradually reduced. The $\mathrm{pH}$ of water ranged from 7.60 to $7.31,7.40$ to $7.70,7.86$ to 7.45 , and 7.19 to 7.21 in manures $1,2,3$, and 4, respectively, throughout the study period. Dissolved oxygen level was not significantly $(\mathrm{P}>0.05)$ higher in the culture system fertilized with compared to the other treatments throughout the study period. 


\title{
International Advanced Research Journal in Science, Engineering and Technology
}

\author{
Vol. 8, Issue 12, December 2021
}

DOI: $10.17148 /$ IARJSET.2021.81202

\section{Relative Growth Rate (RGR) and Production}

The RGRs of L. minor were 60.67, 37.76 and $64.33 \mathrm{~g}$ /day by the end of one month respectively (Table 1). The results recorded was in agreement with the work of Skillicorn et al. (1993) that reported that biomass of duckweed doubles in 2 to 3 days. The duckweed was first harvested after 7 days of introduction. Macrophyte was harvested four time during 1 month culture period. $99.90 \%, 133.60 \%$, and $99.90 \%$ macrophyte was harvested at the time of the experiment and all plants were collected at the fourth harvest which marked the end of the experiment as shown in Table 1.

\section{Proximate Composition of $L$. minor}

Proximate composition analysis of duckweed showed that there was difference between the macrophytes cultured with Poultry droppings, pig dungs and cattle dungs. Though there were no significant differences among the proximate parameters investigated in T1, T2 and T3 $(\mathrm{P}>0.05)$. Balancing these higher levels, carbohydrate content was lower in macrophytes cultured in $\mathrm{T} 3$, followed by $\mathrm{T} 1$ while $\mathrm{T} 2$ recorded highest though there was no significant difference $(\mathrm{P}>$ 0.05) (Table 2).

The proximate composition of the cultured duckweed are presented in Table 2 . The crude fibre, crude protein, dry matter, carbohydrate, fat, moisture content, ether extract and ash values respectively, for the duckweed from the three investigated media, dry matter $(9.89 \%$ in $\mathrm{T} 1,7.53 \%$ in $\mathrm{T} 2$ and $8.15 \%$ in $\mathrm{T} 3)$, moisture content $(9.89 \%$ in $\mathrm{T} 1,7.53 \%$ in $\mathrm{T} 2$ and $8.15 \%$ in $\mathrm{T} 3)$ and fat $(2.24 \%$ in $\mathrm{T} 1,1.95 \%$ in $\mathrm{T} 2$ and $2.28 \%$ in $\mathrm{T} 3)$ fractions respectively. The carbohydrate content $(55.00 \%$ in $\mathrm{T} 1,58.07 \%$ in $\mathrm{T} 2$ and $54.00 \%$ in T3) in this study was found higher than the range of $14.1-43.6 \%$ reported by Landolt and Kandeler, (1987). The crude fibre, for duckweed cultured in all the three media this study were $12.24 \%$ in T1, $10.52 \%$ in T2 and $11.78 \%$ in T3 respectively. These values were higher than $7-10 \%$ for duckweed grown in nutrient-rich pond as opposed to $11-17 \%$ for duckweed in nutrient poor water (Leng et al., 1995). This observed difference may be due to species cultivated in this study as Lemna is known to be complex within the family. However, the ash values obtained in this study $(13.14 \%$ in $\mathrm{T} 1,11.75 \%$ in $\mathrm{T} 2$ and $13.95 \%$ in $\mathrm{T} 3$ ) for all media respectively were in line with the ash value of $12-18 \%$ reported by Anya and Ayuk, (2018) and Leng et al. (1995). Generally, fibre and ash values reported in this study were higher than reported values. This observation is in line with the reports of Anya and Ayuk, (2018) and Skillicorn et al. (1993) that fibre and ash contents are usually higher and protein content, lower in duckweed colonies with slow growth, starvation (nutrient deficient ponds) and ageing which corroborates the findings in this study. The ether extract content of all the cultured duckweed (1.20\%\% in T1, 1.63 in T2 and 1.52 in T3 (1.5 and $1 \%)$ respectively, fell below $1.8-2.5 \%$ in duckweed species grown in nutrient - poor water and 3-7\% for duckweed grown in nutrient - rich water as reported by Leng et al. (1995). However, the species cultured and the respective or varied culture mediums might be responsible for the observed differences (Anya and Ayuk, 2018).

Although, the nitrogen free extract value was higher for the duckweed cultured with cattle dung (T2) culture media and poultry manure media (T1) were more than Pig dung culture media, results of other proximate fractions suggest lower nutrient levels of the natural pond which further shows that the nutrient composition of duckweed will vary depending on the nutrient content of the growth medium. The crude protein for all the cultured duckweed was $7.50 \%$ in T1, 10.18\% in T2 and $9.55 \%$ in T3. This value was lower than 15-35\% range reported for CP by Leng et al. (1994). However, the crude protein of all the cultured media pond duckweed were lower than 45\% CP reported by Mibagwu and Adeniji (1988) and $21 \%-42 \%$ by Anya and Ayuk, (2018) as well as lower than $20.9 \%$ CP reported by Leng et al. (1995) and 18.3\% CP reported by Ahammad et al. (2003) though, not in the same type of culture media. However, the crude protein of $7 \%$ - $10 \%$ reported in this study fell within the range of $7-45 \%$ (Culley et al., 1981) but not as in $43 \%$ as reported by Leng et al. (1995). The result of crude protein obtained in this study agrees with the report of Hillman and Culley et al. (1981). Thus, it can be effectively used as a protein supplement in livestock and poultry diets.

\section{REFERENCES}

Acosta, N. F. (2004). Duckweed invasion in lake maracaibo. Retrieved from National Areonautic and Space Association website: http://earthobservatory.nasa.gov

Ahammed, M. U., Swapon, M. S. R., Yeasmin, T. Rahman, M. S. and Alli, M. S. (2003). Replacement of sesame oil cake by duckweed (Lemna minor) in broiler diets. Pakistan J. Bio, Sci. 16, 1450-1453.

Anya, M. I. and Ayuk, A. A. (2018). Growth Characteristics and Proximate Profile of Duckweed (Lemna minor) Cultured in Calabar - Humid Zone of Nigeria. International Journal of Advances in Agricultural Science and Technology, 5:9, pg. 38-43.

Association of Official Analytical Chemists AOAC (2000) Official methods of analysis. Association of official analytical chemist. Washington D. C. (15) 117.

Cross, J. W. (2002). The Charms of Duckweed http://www.mobot.org/jwcross/duckweed.htm (10 Nov. 2019).

Culley, D. D., Rejmankoua, E., Kvet, J. and Frye, J. B. (1981). Production, chemical quality and use of duckweeds (Lemnaceae) in aquaculture, waste management and animal feeds. Journal of the world Mariculture Society 12: $27-49$.

Journey, W. K., Skillicorn, P., and Spira, W.(1991). Duckweed Aquaculture: A New Aquatic Farming System for Developing Countries, The World Bank.

Landolt, E. and Kandeler, R. (1987). Biosystematic investigations on the family of duckweed (Lemnaceac). Published in the Geobotanischen Instituties ETH, Stiftung Zurich. 


\section{International Advanced Research Journal in Science, Engineering and Technology}

\section{Vol. 8, Issue 12, December 2021}

\section{DOI: 10.17148/IARJSET.2021.81202}

Leng, R. A. (1999). Duckweed: A Tiny Aquatic Plant with Enormous Potential for Agriculture and Environment, Food and Agriculture Organization (FAO) of the United Nations, Rome, Italy, 1999, on 24 November, 2019. http://www.fao.org/ag/AGAinfo/resources/documents/DW/Dw2.htm,

Leng, R. A., Stambolie, J. H and Bell, R. E. (1995). Duckweed a potential high protein feed resource for domestic animals and fish. Livest. Res. Rural Develop. 7(1)

Li, X.; Wu, S.; Yang, C.; Zeng, G. (2020). Microalgal and duckweed based constructed based constructed wetlands for swine wastewater treatment: A review. Bioresour, Tehnol. 318, 123858.

Mibagwu, I. G and Adeniji, H.A. (1988). The nutritional content of duckweed (Lemna paucicoslata Hegelm) in the Kainji Lake area, Nigeria. Aqua. Bot. 29:357-366.

Skillicorn, P., Spira, W. and Journey, W. (1993). Duckweed aquaculture - A New Aquatic Farming System for Developing Countries. The World Bank Washington, D.C. PP 76.

Skillicorn, P., Spira, W. and Journey, W. (1993). Duckweed aquaculture - A New Aquatic Farming System for Developing Countries. The World Bank Washington, D.C. PP 76.

Zhuang, X. (2014). “Lemna minor,” The IUCN Red List of Threatened Species, 2014. http://www.iucnredlist.org/details/164057/0 Downloaded on 24 November, 2019.

Ziegler, P., Adelmann, K., Zimmer, S., Schmidt, C. and Appenroth, K. J.(2015). "Relative in Vitro Growth Rates of Duckweeds (Lemnaceae) - The Most Rapidly Growing Higher Plants," Plant Biology, 17:(1), pp. 33-41. 